\title{
A EVASÃO EM UM CURSO DE PSICOLOGIA: UMA ANÁLISE QUALITATIVA
}

\author{
Alexandre Kurtz dos Santos Sisson de Castro² \\ Marco Antônio Pereira Teixeira \\ Universidade Federal do Rio Grande do Sul, Porto Alegre-RS, Brasil
}

\begin{abstract}
RESUMO. O objetivo deste estudo foi descrever aspectos da experiência acadêmica que podem estar associados à evasão em um curso de Psicologia. Além disto, objetivou-se observar se categorias elaboradas a partir da literatura que pudessem servir de base para a análise da experiência acadêmica em estudos qualitativos sobre evasão. Participaram seis ex-alunos, adultos jovens, que haviam cursado entre dois e cinco semestres. Foram realizadas entrevistas individuais, que posteriormente foram submetidas à análise de conteúdo. Como resultados pôde-se observar que estão associados à evasão tanto aspectos relacionados ao indivíduo (baixa motivação; dificuldades de relacionamento; baixo comportamento exploratório) quanto aspectos relacionados à instituição (relacionamento frio com professores; focalização do currículo em algumas áreas específicas; conflitos entre visões diferentes da Psicologia, levando a divergências internas). Salienta-se a necessidade de serem realizadas ações que ajudem a preparar o indivíduo para o ingresso na universidade, além de aconselhamento de carreira aos alunos que enfrentam dúvidas e dificuldades em sua trajetória acadêmica.
\end{abstract}

Palavras-chave: Evasão; Psicologia; Ensino superior.

\section{DROPOUT AT A PSYCHOLOGY COURSE: A QUALITATIVE ANALYSIS}

ABSTRACT. The aim of this study was to describe aspects of the academic experience that may be associated with dropout at a psychology course. In addition, it aimed to analyze if literature-based categories could provide a basis for the analysis of academic experience in qualitative studies of dropout. Participants were six former students, young adults, who were enrolled between 2 and 5 semesters before attrition. Individual interviews were conducted and subsequently submitted to content analysis. Results showed that dropout was related to individual factors (low motivation, difficulty in relationships, low exploratory behavior) as well as institutional ones (cold relationship with faculty, curriculum focused on specific areas; conflicts between different views of psychology, leading to internal disagreements within course functioning). It is concluded that interventions have to be offered in order to help students who are planning to enroll higher education courses in order to make better decisions, as well as career counseling for those who face doubts and difficulties in their academic trajectories.

Keywords: Dropout; Psychology; Higher education.

\section{LA EVASIÓN EN UN CURSO DE PSICOLOGÍA: UN ANÁLISIS CUALITATIVO}

RESUMÉN. El objetivo de este estudio fue describir los aspectos de la experiencia académica que pueden estar asociados con el abandono de un curso de psicología. Además el objetivo de observar si las categorías extraídas de la literatura podrían servir de base para el análisis de la experiencia académica en estudios cualitativos sobre la evasión. Participaron seis exalumnos, adultos jóvenes, que fueron enrolados entre los 2 y 5 semestres. Las entrevistas individuales se realizaron posteriormente sometidos a análisis de contenido. Cómo podría observar resultados que la evasión está asociados con los aspectos relacionados a los individuos (baja motivación, dificultades en las relaciones, el comportamiento exploratorio bajo) en relación con la institución (relación fría con los maestros, el enfoque curricular en áreas específicas, los conflictos entre diferentes puntos de vista psicología, lo que lleva a desacuerdos internos). Hacemos hincapié en la necesidad de tomar medidas para ayudar a preparar al individuo para el ingreso a la universidad, y orientación profesional a los estudiantes que se enfrentan a las dudas y dificultades en sus trayectorias académicas.

Palabras-clave: Evasión; Psicología; Educación superior.

\footnotetext{
${ }^{1}$ Apoio: Capes - REUNI.

2 Endereço para correspondência: Rua Ramiro Barcelos, 2600, sala 117, CEP 90035-003, Santana, Porto Alegre-RS. E-mail: alexandreksscastro@gmail.com
} 
Em um contexto de expansão e democratização do Ensino Superior, estudos sobre evasão são importantes para que possam ser promovidas ações que minimizem a ocorrência desse fenômeno. Em contextos universitários como o norte-americano, onde o ingresso se dá para o ensino universitário de um modo geral e não necessariamente para cursos profissionais específicos, a evasão pode ser definida como o abandono do Ensino Superior. No contexto nacional, onde a entrada no Ensino Superior se dá para um curso específico, a evasão ganha nuanças diferentes. No Brasil, o aluno pode abandonar o curso e migrar para outro na mesma instituição (evasão de curso), como também pode mudar de instituição não necessariamente mudando de curso (evasão de instituição), ou ainda, pode evadir-se do sistema de ensino superior (evasão de sistema). Esta última transição é mais assemelhada com a evasão estudada no contexto norte-americano (Comissão Especial de Estudos sobre Evasão, 1996; Pascarella \& Terenzini, 2005).

A importância do estudo da evasão está, fundamentalmente, nas implicações que este fenômeno traz tanto para quem se evade quanto para as instituições de ensino envolvidas. Para quem se evade a mudança pode ter um significado positivo - por exemplo, quando um aluno insatisfeito com sua escolha de curso ou instituição realiza uma troca de curso que, de certa forma, dê um rumo melhor à sua carreira. Por outro lado, a evasão pode trazer prejuízos financeiros para o aluno ou sua família, que pode ter investido uma quantia importante em cursos, congressos ou mesmo mensalidades, além de algum possível prejuízo psicológico, dependendo dos motivos associados à evasão. Pelo lado institucional, destacam-se alguns prejuízos, como o investimento público perdido (instituições públicas) e o prejuízo financeiro em relação aos lucros esperados (instituições privadas). Soma-se a estes prejuízos o fato de que a vaga ocupada pelo aluno evadido, que não vai se formar e assim trazer um retorno social, poderia ter sido preenchida por outro aluno (Ristoff, 1999; Silva Filho, Motejunas, Hipólito \& Lobo, 2007).

Em busca da compreensão deste fenômeno, diversos modelos teóricos de evasão têm sido propostos, especialmente nos Estados Unidos (Berger \& Milem, 1999; Cabrera et al., 1993; Robbins et al., 2004; Tinto, 1975). Destes modelos, o mais parcimonioso é o de Robbins et al. (2004). Os autores elaboraram seu modelo a partir de uma meta-análise de 109 estudos sobre permanência e desempenho no Ensino Superior. Assim, buscaram um modelo que abarcasse o maior número possível de variáveis, considerando aspectos tanto educacionais e organizacionais quanto psicológicos e motivacionais. Foram destacados nove aspectos responsáveis pela permanência e pela performance acadêmica: (a) motivação para realização; (b) metas acadêmicas; (c) compromisso com a instituição; (d) suporte social percebido; (e) envolvimento social; (f) autoeficácia acadêmica; (g) autoconceito; (h) habilidades acadêmicas; (i) influências do contexto acadêmico, divididas em três eixos: i) as condições dadas em nível de suporte financeiro e benefícios, ii) o tamanho da instituição, ou número de alunos na instituição e, iii) a forma de seleção da instituição. Algumas pesquisas têm utilizado este modelo como referência e obtido resultados satisfatórios (por exemplo, Sameano, Allen, Robbins \& Phelps, 2010).

As pesquisas sobre evasão no Brasil tendem a ser descritivas e muitas vezes não consideram os modelos teóricos existentes sobre evasão. São pesquisas em grande parte conduzidas com 0 objetivo de elaborar diagnósticos descritivos de cursos ou instituições específicos (por exemplo, Gomes, Monteiro, Damasceno, Almeida, \& Carvalho, 2010; Palharini, 2008); contudo, existem na literatura nacional pesquisas que buscam estabelecer uma discussão mais teórica, estudando a evasão principalmente a partir de modelos mais tradicionais, como o de Vincent Tinto (Bardagi \& Hutz, 2005; Mercuri \& Polydoro, 2004). Apesar de predominante, tanto no Brasil quanto no exterior, a teoria de Tinto tem se mostrado insuficiente para descrever satisfatoriamente a questão da evasão ou da permanência dos estudantes brasileiros em seus cursos (Mercuri \& Polydoro, 2004). Por exemplo, o compromisso com a instituição e o compromisso com a meta de graduar-se, pontos centrais do modelo de Tinto, não foram observados, nos estudos brasileiros, como sendo tão importantes nas decisões de permanecer ou evadir-se quanto nos estudos norteamericanos. Assim, foi proposto que o compromisso com o curso em si (envolvendo os sentimentos de segurança e satisfação quanto à escolha do curso e da profissão) seja considerado 
nas pesquisas nacionais (Mercuri \& Polydoro, 2004).

De forma geral, tomar decisões e mudar os rumos da vida em diversos aspectos, especialmente no profissional, tem sido uma tendência do mundo contemporâneo (Savickas, 1997). O momento de ingresso no Ensino Superior é certamente um destes momentos de mudança. Um dos mecanismos mais importantes nestes momentos de transição e decisão é o comportamento exploratório, ou seja, a busca do indivíduo por informações e conhecimentos sobre si e sobre ambiente (Teixeira, Bardagi \& Hutz, 2007). Evidências de relação entre o baixo nível de comportamento exploratório relacionado ao curso e à profissão e a evasão têm sido observadas em algumas pesquisas (Andriola, Andriola \& Moura, 2006; Bardagi, 2007; Ribeiro, 2005).

Observando-se os modelos propostos na literatura internacional e o panorama das pesquisas nacionais, verifica-se a necessidade de expandir as investigações sobre os modelos de evasão no Ensino Superior, procurando-se construir ou adaptar os modelos existentes às peculiaridades do sistema de ensino brasileiro. A partir da elaboração ou adaptação de um modelo os pesquisadores interessados na temática poderão fazer diagnósticos específicos ainda mais qualificados. Dado este quadro, esse estudo teve como objetivo geral descrever qualitativamente aspectos referentes à experiência acadêmica manifestada por alunos evadidos do curso diurno de Psicologia da Universidade Federal do Rio Grande do Sul UFRGS - que podem estar associados ao fenômeno da evasão. O curso de Psicologia da UFRGS é gratuito e um dos mais concorridos no Estado, e obteve grau máximo nas avaliações conduzidas pelo Ministério da Educação. Atualmente o curso oferece uma turma no turno noturno e uma no diurno, mas este estudo foi conduzido apenas com alunos que estudam no período diurno, pois o curso noturno era muito recente quando foi realizada a coleta de dados.

Buscou-se especialmente, de forma exploratória, observar se o modelo de Robbins et al. (2004) poderia servir de base para a análise da experiência acadêmica em estudos sobre evasão. Para tanto, Foram utilizados como categorias de análise a priori os fatores elencados por Robbins et al. (2004), considerando-se dentro das categorias do modelo os aspectos vocacionais descritos na literatura nacional como fatores importantes para a evasão (Bardagi \& Hutz, 2005; Mercuri \& Polydoro, 2004).

\section{MÉTODO}

\section{Delineamento}

Empregou-se um delineamento de estudo de caso coletivo (Stake, 1994), qualitativo e exploratório. Optou-se por este delineamento porque o objetivo do estudo foi descrever aspectos associados ao fenômeno da evasão no curso de Psicologia da UFRGS como um todo, e não o entendimento específico de casos individuais.

\section{Participantes}

Participaram dessa pesquisa seis ex-alunos (quatro mulheres e dois homens) do curso de Psicologia diurno, sendo três oriundos do currículo antigo (ingresso até 2006) e três do currículo novo (ingresso após 2007). Todos eram adultos jovens, com idades entre 19 e 26 anos, e haviam frequentado entre dois e cinco semestres do curso de Psicologia. Conforme dados do sistema informatizado da universidade, houve 32 casos de evasão entre os ingressantes das turmas de 2004 a 2009.

\section{Instrumento}

Utilizou-se uma entrevista semiestruturada com roteiro flexível, inspirada no modelo de entrevista proposto por Bardagi (2007). A entrevista abordou três temas amplos, que buscaram mapear a trajetória de vinculação e desvinculação do curso: 1) Primeira Escolha, que tratou da forma de escolha do curso, do apoio de pais e pares, das informações e expectativas preliminares em relação ao curso, à profissão, etc.; 2) Vivência Acadêmica, que tratou de aspectos relativos à convivência e a experiências relativas ao período em que o ex-aluno frequentou o curso; 3) Evasão, Situação Atual e Possíveis Intervenções, que tratou de aspectos relacionados à evasão, situação profissional e acadêmica atual, e ainda sobre sugestões de possíveis intervenções que, na visão do entrevistado, poderiam contribuir para a não evasão. 


\section{PROCEDIMENTOS}

Os potenciais participantes foram elencados a partir dos registros da Comissão de Graduação do Curso de Psicologia (COMGRAD) e divididos em duas categorias: ingressantes no currículo novo e ingressantes no currículo antigo. Os entrevistados foram sorteados entre os potenciais participantes. Os selecionados foram contatados por telefone ou e-mail diretamente pela equipe de pesquisa e convidados a participar do estudo. As entrevistas foram realizadas pelo mesmo entrevistador, gravadas e transcritas na sua íntegra para análise. O estudo foi conduzido após a aprovação do Comitê de Ética em Pesquisa do Instituto de Psicologia da UFRGS. Antes de conceder a entrevista os participantes foram esclarecidos acerca dos objetivos da pesquisa e dos procedimentos, e realizaram a leitura e assinatura do Termo de Consentimento Livre e Esclarecido. $\mathrm{O}$ critério de saturação de entrevistas foi utilizado para delimitar o tamanho da amostra.

\section{Análise dos dados}

As entrevistas foram analisadas qualitativamente através de análise temática de conteúdo, tendo o corpus das entrevistas como objeto de análise (Bardin, 1977). Utilizou-se como ferramenta auxiliar no processo de codificação das entrevistas o software Atlas.ti, versão 5.17. A análise foi realizada a partir de categorias previamente definidas, no caso, os fatores da experiência universitária relacionados à evasão elencados por Robbins et al. (2004). Dessa forma, uma vez transcritas as entrevistas, estas foram analisadas procurando-se identificar passagens relacionadas a cada categoria que descrevessem a experiência vivida pelos participantes. Não foram observadas diferenças relacionadas a questões curriculares específicas entre os alunos do currículo antigo e do novo, tendo-se optado então por fazer uma análise conjunta dos dados, e não por grupos.

\section{RESULTADOS}

Como um dos objetivos do estudo foi observar se as categorias prévias seriam adequadas para a análise da evasão em estudos qualitativos, os resultados são apresentados partindo da definição teórica das categorias, que são então ilustradas com excertos que revelam as nuanças experienciais de cada fator potencialmente associado à evasão. Optou-se por não relacionar os excertos aos participantes da pesquisa, mesmo através de alguma identificação fictícia, para garantir maior sigilo dos sujeitos. As categorias "autoeficácia acadêmica" e "habilidades acadêmicas" foram reunidas em uma só, devido à similaridade de seus conteúdos. As categorias "autoconceito" e "influências do contexto acadêmico" foram modificadas em sua definição original a fim de englobar elementos relacionados ao desenvolvimento vocacional descritos na literatura nacional e aspectos específicos do contexto local.

\section{Motivação para realização}

A motivação para realização pode ser conceituada como a motivação para o sucesso e para a realização das tarefas acadêmicas (Robbins et al. 2004); ou seja, para completar a tarefa final em uma graduação, que é a obtenção do grau, o aluno deve estar motivado para realizar as tarefas exigidas no curso. Neste sentido, observou-se que a insuficiência de motivação para superar barreiras ou lidar com experiências que não atendiam as expectativas foi um fator que contribuiu para a decisão de abandono, como ilustrado na seguinte fala: "A questão era que era pouco aproveitado (...) Até os professores mesmo, às vezes eles iam pras aulas com aquele data show, tudo o que a gente já tinha lido nos textos (...) não me cativou como deveria ser...".

\section{Metas acadêmicas}

Nesta categoria observam-se a definição, a persistência e o compromisso com metas acadêmicas em um curso de graduação, em especial com a meta de graduar-se (Robbins et al., 2004). Em relação à Psicologia, os ex-alunos não expressaram claramente o compromisso com a meta de graduar-se no curso, o que é óbvio, uma vez que eles não o concluíram; mas se observarmos a questão pelo prisma do interesse em ter um diploma de nível superior, poderemos perceber que a meta de obter uma graduação ainda mostrou-se importante, podendo ser fundamental na formação superior futura destes alunos, como explicitado na fala do ex-aluno: "Eu pensava, eu tinha o plano de fazer outra faculdade. Isso eu não abria mão. Tenho que fazer alguma faculdade". 


\section{Compromisso com a instituição}

O compromisso com a instituição relaciona-se com a importância de ser aluno de uma determinada universidade, com a confiança e a satisfação no tocante à escolha da instituição e à satisfação percebida com esta escolha durante a experiência acadêmica (Robbins et al., 2004; Tinto, 1975). Nas falas dos participantes pôde-se observar que, mesmo não tendo sido suficiente para evitar a evasão de curso, o compromisso com a instituição contribuiu para a não evasão do sistema de ensino superior, como sugere a fala a seguir: "Na verdade meu maior objetivo assim era passar na UFRGS. (...) Minha preocupação maior era passar na UFRGS, pra não ter o peso dos meus pais terem que pagar uma faculdade particular".

\section{Suporte social percebido}

Trata-se do suporte social percebido pelo estudante durante seu processo de escolha e vivência universitária. Engloba o apoio de pais e pares percebido em relação à sua condição de estudante e em relação às decisões tomadas por este (Robbins et al, 2004). Observam-se dois momentos distintos relativos ao suporte social percebido pelos participantes: o apoio ou não à escolha do curso de Psicologia; e o suporte percebido no momento da evasão. Foram observados tanto casos onde houve apoio incondicional à escolha do curso e/ou à evasão do curso quanto outras situações em que família e amigos não apoiaram as decisões de carreira dos estudantes. Contanto, não foi observado nas falas, em nenhum momento, que a falta de apoio tenha influenciado diretamente na decisão de evasão, bem como que o apoio tenha evitado a saída. De modo geral os evadidos do curso de Psicologia relataram ter diálogos frequentes com os pais sobre as decisões na carreira, tanto no momento da escolha quanto no da evasão, como observado por um entrevistado: "Eu cresci num ambiente em que a gente falava muito sobre a importância do estudo. (...) Meu pai principalmente sempre incentivou essa questão de estudar, de fazer universidade, de fazer pós-graduação, mestrado, doutorado".

\section{Envolvimento social}

O envolvimento social engloba a sensação de pertencimento ao ambiente da instituição e a qualidade das relações com os colegas, professores e outros funcionários do meio universitário (Robbins et al., 2004). Observou-se que em alguns casos o envolvimento com os colegas de curso dificultou, mas não evitou, a evasão do curso. Deste modo, ter criado laços de amizade com outros alunos foi uma questão ponderada quando da evasão, mas não foi decisiva nos casos observados, como ilustrado na fala a seguir: "O problema era que na verdade eu não queria estar na Psicologia, mas eu queria continuar com os meus amigos.(...) Talvez se eu não tivesse me aproximado tanto das pessoas teria sido mais fácil pra mim largar o curso".

Por outro lado, observou-se que para outros alunos este envolvimento não se deu de forma satisfatória. As principais dificuldades descritas foram relativas a diferenças de valores e à sensação de não pertencimento ao grupo. Esta última foi importante no processo de decisão de evadir do curso, como se pode observar no relato de um dos evadidos: "às vezes eu não conseguia me identificar muito com as pessoas. (...) Acho que eu não consegui desenvolver um sentido como fazendo parte daquele grupo".

Em relação ao envolvimento social com os professores, observou-se uma sensação de distanciamento dos professores por parte dos alunos evadidos. Este distanciamento foi percebido inclusive em comparação com os professores do Ensino Médio: "Eu acho que eles (os professores) podiam ser um pouco mais próximos assim... conhecer um pouco mais o aluno assim. (...) Até porque a gente acaba não se identificando muito assim com o professor. Fica uma coisa mais distante mesmo".

\section{Autoeficácia acadêmica e habilidades acadêmicas}

A autoeficácia acadêmica é definida como a percepção geral de capacidade de sucesso no meio acadêmico, enquanto as habilidades acadêmicas referem-se às habilidades cognitivas, comportamentais e afetivas específicas que permitem a realização a contento de tarefas acadêmicas como o manejo do tempo, hábitos de estudo e habilidades de comunicação (Robbins et al., 2004). Não foram observadas entre os entrevistados menções explícitas de dificuldades para conseguir dar conta do curso devido a exigências de desempenho que julgassem estar além das suas capacidades. Pelo contrário, a facilidade com que cumpriam as tarefas durante a graduação foi citada inclusive como um fator 
desmotivador, como observado na fala de um exaluno: "Eu imaginei que fosse ser mais difícil intelectualmente (...) Não sei, eu achava fácil, (...) eu percebia que às vezes aquilo ali era uma perda de tempo assim, porque era óbvio que aquilo ali era daquele jeito".

Não obstante, a percepção de não possuir outras competências necessárias à vida acadêmica foi um fator que se mostrou influente na decisão de evasão. Por exemplo, a falta de habilidade para apresentar-se em grupo, associada a um sentimento de incapacidade para lidar com esse tipo de limitação, contribuiu para a decisão de um entrevistado de evadir-se: "Eu não conseguir falar em público, que era uma coisa que na época era muito difícil pra mim. Apresentar trabalho, o julgamento das pessoas era muito importante (...) pra mim era muito estressante, mas era mais uma coisa minha mesmo".

\section{Influências do contexto acadêmico}

Conforme definição de Robbins et al., (2004), as influências do contexto acadêmico, em sentido amplo, incluem fatores institucionais que de algum modo podem afetar a disponibilização aos alunos de recursos que favorecem a persistência nos cursos. Segundo os autores, esses fatores podem englobar: (a) as condições dadas pela universidade em nível de suporte financeiro e benefícios; (b) o tamanho da instituição, medida pelo número de alunos na instituição, e (c) a forma de seleção da instituição, ou o grau de dificuldade de nela ingressar (relacionado ao prestígio). Não houve nenhuma referência, por parte dos estudantes, a estes fatores institucionais especificamente; contudo, considerando-se que no país o ingresso para o ensino superior se dá para um curso específico de uma instituição específica, os aspectos relativos ao contexto do curso podem ser incluídos nesta categoria. De fato, aspectos institucionais ligados à estrutura curricular e ao funcionamento do curso foram citados como elementos que contribuíram para a insatisfação com o curso e a decisão de abandoná-lo. Em termos de currículo, foi salientada a falta de conteúdos considerados importantes, em especial quando curso foi comparado ao de outras universidades:

Eu vi que se eu tivesse cursado Psicologia em outra universidade talvez eu tivesse continuado no curso. Porque o viés da UFRGS é muito [entrevistado menciona uma ênfase] (...) Agora, na [cita outra universidade], tem mais um viés mais voltado pra mercado de trabalho, pra atuação, pra empresa, pra psicologia do trabalho. Talvez eu tivesse suportado aquelas coisas que eu não gostava por ter mais outras características no curso da outra universidade.

Já em termos de funcionamento do curso, sua divisão em vertentes da Psicologia associadas aos departamentos do Instituto de Psicologia foi mencionada como fator que contribuiu para a evasão. Este fato, segundo os entrevistados, gerava distanciamento tanto entre os departamentos quanto entre os próprios alunos:

"O que pôs em dúvida a minha escolha era a ruptura departamental que tinha aqui dentro (...) Porque as visões são muito diferenciadas dentro dos departamentos. (...) Dentro do Instituto a coexistência era impossível. (...) A turma acabou segmentando também".

\section{Autoconceito global e outros aspectos vocacionais}

O autoconceito global foi definido por Robbins et al. (2004) como o sistema de crenças e percepções que um indivíduo tem sobre si mesmo e sobre suas ações no ambiente, estando bastante associado aos conceitos de autoestima e autoeficácia globais. De fato, uma percepção de inadequação entre as características pessoais e a imagem construída de um suposto perfil profissional ideal foi um fator que contribuiu para a decisão de evadir-se, na medida em que produziu um sentimento de incongruência e insatisfação com o contexto em que o aluno estava inserido.

Eu comecei a perceber que eu não tava feliz (...) que eu tinha me enganado em relação ao meu perfil, e o que um psicólogo precisa ter pra estar bem na sua profissão. Eu vi que eu era muito mais... O psicólogo ele tem que ser quieto, ele tem ouvir, eu gosto de falar, eu gosto de doar, entende? Eu gosto de expor uma ideia. Não tenho perfil de ouvinte "ahã, ahã, ahã. Deu, acabou o horário".

Observou-se também, como elemento motivador da evasão, uma diferença entre as expectativas que os alunos tinham sobre a própria prática profissional do psicólogo e aquilo que 
haviam conseguido vislumbrar dentro do curso como possibilidade de atuação. O descompasso entre o esperado e o percebido foi, em parte, decorrência do nível superficial de conhecimentos que tinham sobre o curso e a profissão à época da escolha, como indicado na fala: "...eu perceber que o psicólogo não fazia aquilo que eu imaginava (...) eu ia pegar as pessoas mal e deixar normais. Eu não ia pegar as pessoas bem e deixar melhor ainda (...) ia trabalhar com doença e não saúde".

A ideia dos alunos sobre a Psicologia, de forma geral, ou se restringiam à Psicologia clínica ou, se sabiam que havia outras áreas, não tinham noção de como se dava o trabalho propriamente dito. Sobre o curso especificamente, observou-se que os evadidos não tinham uma noção clara dos conteúdos que eram estudados em um curso de Psicologia. Outro ponto de decepção observado no tocante à profissão de Psicologia foi a percepção de uma dissonância entre as expectativas de retorno financeiro e 0 que percebiam como oportunidades a partir da formação profissional. Esta visão negativa sobre o futuro em termos de trabalho e remuneração foi construída, em parte, a partir da observação de colegas que estavam se formando e procurando se colocar no mercado de trabalho: "As pessoas que eu conhecia se formando, (...) não estavam se dando muito bem (...) Estavam com problemas pra começar o trabalho, estavam recorrendo a fazer concursos, pra um trabalho que tangenciava a área que eles gostavam".

\section{DISCUSSÃO}

Quanto à motivação para realização do aluno, parece importante 0 papel de motivador do professor, já que a busca por excelência, por parte do estudante que não possui uma motivação mais intrínseca, vai depender da estimulação externa. Mais do que um simples transmissor de conhecimento, o aluno espera que o professor seja um modelo, uma pessoa que o cative e o leve a gostar da área que ensina. Por outro lado, o Ensino Superior exige que 0 indivíduo desenvolva autonomia e responsabilidade em relação às suas escolhas acadêmicas (Teixeira, Dias, Wottrich \& Oliveira, 2008). O desenvolvimento precário desta autonomia, associado à não identificação com o curso e práticas não cativantes de ensino, pode levar à falta de motivação para realizar as tarefas do curso, ou mesmo a uma acomodação do aluno, no sentido de este limitar-se a cumprir as exigências mínimas colocadas pelo curso, deixando de aproveitar ao máximo a experiência de formação para o seu crescimento profissional e pessoal.

Os ex-alunos, mesmo não apresentando um compromisso com a meta de graduar-se no curso de Psicologia, demonstraram a intenção de se graduar em outro curso. Além disso, os entrevistados também mostraram compromisso com a instituição. Embora estes dois fatores não tenham impedido a evasão do curso de Psicologia, eles tendem a evitar a evasão de sistema (Pascarella \& Terenzini, 2005; Robbins et al., 2004; Tinto, 1975).

No que concerne ao suporte social percebido, observou-se neste estudo que, de forma geral, os evadidos relataram a presença de diálogos frequentes tanto no momento da escolha do curso quanto no da evasão. No estudo de Bardagi e Hutz (2008), do qual participaram oito alunos de cursos e áreas diferentes, observou-se que estes diálogos limitavam-se à questão do vestibular e da escolha ou não do curso. Talvez a diferença destes resultados se deva às amostras, uma vez que com os ex-alunos de Psicologia, um curso que teoricamente exige do estudante uma tendência maior à abertura, à escuta, ao diálogo e às relações humanas, o diálogo com os pais foi enfatizado. Por outro lado, os resultados dos dois estudos convergiram em alguns pontos: (a) mesmo relatando maior diálogo sobre carreira, futuro e vivências acadêmicas, também foi observada nessas conversas ênfase na importância de conseguir um diploma de nível superior; e (b) os pais foram citados como apoio de uma maneira mais evidente do que os amigos. Mesmo não tendo influência direta na decisão de evadir-se, observouse que, em casos de apoio de pais e pares à saída, esta pareceu ocorrer de forma menos traumática (Bardagi \& Hutz, 2008).

O envolvimento social é um dos pilares de diversos modelos internacionais de evasão (Berger \& Milem, 1999; Cabrera et al., 1993; Robbins et al., 2004; Tinto, 1975). Na literatura nacional o envolvimento social também é apontado por diversas pesquisas como importante para adaptação do estudante à universidade (por exemplo, Bardagi \& Hutz, 2012; Schleich, Polydoro \& Santos, 2006, Teixeira, Castro \& Zoltowski, 2012). Os resultados deste estudo reforçam a importância dada ao tema na literatura. Mesmo que não tenha sido decisivo na evasão, o envolvimento social permeou o discurso dos entrevistados tanto 
positiva quanto negativamente. As principais dificuldades descritas foram relativas a diferenças de valores e à sensação de não pertencimento ao grupo, das quais esta última, no presente estudo, foi importante no processo de decisão de evadir-se do curso. Estes resultados estão de acordo com achados da literatura internacional em relação à importância da sensação de pertencimento na questão da permanência do aluno (Haussmann, Ye, Schofield \& Woods, 2009). Outro ponto de destaque na literatura no tocante ao envolvimento social são as relações com os professores (Berger \& Milem, 1999; Pascarella \& Terenzini, 2005; Robbins et al. 2004; Tinto, 1975). As relações em questão ultrapassam a simples relação de ensinoaprendizagem em sala de aula. Elas englobam a atenção que os professores dão aos alunos em outros espaços, as relações não formais e o suporte dado aos alunos que os procuram em momentos-chave durante o curso. Nas entrevistas observou-se uma sensação de distanciamento dos professores por parte dos alunos evadidos. Estes resultados podem indicar que os professores do curso deveriam se relacionar de outras formas, aproximando-se mais dos alunos, especialmente nos primeiros semestres do curso.

Um fator não associado diretamente à evasão foi o fator habilidades acadêmicas. Neste ponto, não foi declarada pelos participantes nenhuma grande dificuldade vinculada à capacidade de realizar as tarefas e apropriar-se dos conteúdos do curso. Em cursos reconhecidamente exigentes, como as engenharias, por exemplo, o fraco desempenho dos alunos e sua dificuldade em realizar as tarefas acadêmicas propostas é um fator decisivo no abandono (Silva, Mainier, \& Passos, 2006). Pelo contrário, neste estudo a facilidade com que se cumpriam as tarefas durante a graduação foi citada até mesmo como fator desmobilizador. Por outro lado, a falta de outras competências necessárias para um bom aproveitamento da experiência acadêmica (não necessariamente em termos de notas), como, por exemplo, a habilidade de falar em grupo, mostrou ser um elemento capaz de enfraquecer a vinculação do aluno com o curso, na medida em que, ao não se sentir capaz de reagir adequadamente às demandas do ambiente, - estudante passa também a questionar a adequação da sua escolha. Pôde-se perceber, nesta pesquisa, uma avaliação um tanto ingênua dos alunos quanto ao "ajuste" entre suas características pessoais e a profissão, como se houvesse um perfil profissional único no qual o estudante devesse se "encaixar". Da mesma forma, a visão da profissão apresentada foi um tanto estereotipada, como se não existissem diversas possibilidades de atuação profissional com diferentes tipos de enfoque.

$O$ que faz com que o aluno avalie de uma maneira tão superficial o seu grau de ajustamento à profissão? A resposta parece estar no baixo comportamento exploratório, tanto no prévio à entrada no curso quanto ao que se observa durante o curso. De forma geral, o baixo comportamento exploratório observado neste estudo corrobora resultados de outras pesquisas nacionais, que associam o baixo comportamento exploratório à evasão universitária (Andriola et al., 2006; Bardagi, 2007; Ribeiro, 2005). O ingresso no Ensino Superior, se combinado com 0 baixo comportamento exploratório, faz com que os alunos se deparem no dia a dia do curso com uma realidade que muitas vezes não Ihes agrada. As diferenças observadas, por sua vez, geram sentimentos de insatisfação e insegurança em relação à escolha do curso, e também uma insatisfação com as perspectivas profissionais futuras. Estas insatisfações acabam por diminuir o compromisso do aluno com o curso, fator que está associado à permanência (Mercuri \& Polydoro, 2004); mas em tempos de acesso à Internet cada vez mais facilitado, não parece ser a falta de informações disponíveis a causa do desconhecimento dos alunos sobre as formações universitárias. Assim, reforça-se a necessidade de se investir em ações e intervenções que promovam o comportamento exploratório de modo que alunos já no Ensino Médio busquem informações importantes sobre a profissão almejada e reflitam sobre estas informações, para que esta importante descoberta não ocorra durante a graduação.

Por outro lado, os cursos também devem contribuir para que o comportamento exploratório continue, e até mesmo se amplie durante a experiência universitária. $\mathrm{O}$ que se verificou neste estudo foram algumas decisões de abandono baseadas em informações superficiais e critérios de escolha profissional estereotipados, como se uma possível congruência entre pessoa e curso/profissão fosse algo dado previamente, que não dependesse do esforço pessoal em lidar com as dificuldades e dissabores do curso e da profissão, ao mesmo tempo em que se procura dentro da profissão um "nicho" ocupacional no qual se consiga expressar o autoconceito vocacional. Neste sentido, é necessário que os cursos 
estimulem tanto a exploração de si (do autoconceito) quanto a exploração do ambiente (Teixeira, Bardagi \& Hutz, 2007), a fim de que os estudantes consigam enxergar, para além do curso, possibilidades de atuação profissional compatíveis com seus interesses e características pessoais.

Conforme definição de Robbins et al. (2004), as influências do contexto acadêmico enfocam condições específicas relacionadas à instituição como um todo; contudo, no contexto nacional, com os ingressos destinados para cursos específicos, este foco exclusivo na análise da instituição não parece trazer contribuição significativa, pois entre os cursos de uma mesma área existem variações de valores, enfoques, objetivos, de dificuldade de ingresso, de concorrência por vagas, etc. Estas mesmas diferenças ocorrem entre os cursos em uma mesma universidade. Por exemplo, dificuldades financeiras, apontadas como fator importante na evasão dos alunos em universidades particulares (Ribeiro, 2005), não foram observadas neste estudo, que foi realizado em uma universidade pública. Claro que esta é uma diferença óbvia, mas outras situações mais pontuais podem ser observadas. Por exemplo, mesmo existindo diretrizes curriculares para os cursos de Psicologia (CNE/CES, 2011), cada curso de Psicologia tem peculiaridades na sua grade curricular. Estas peculiaridades são fortemente influenciadas pelas orientações do corpo docente. Esta formatação e a consequente ênfase que cada currículo dá ao seu curso podem ser satisfatórias para alguns alunos e insatisfatórias para outros. Pode-se argumentar que a não percepção, por parte dos alunos, do viés de cada curso em uma mesma área é uma questão de falta de comportamento exploratório. Por outro lado, as diretrizes curriculares de Psicologia falam em proporcionar ao aluno uma formação que possibilite a compreensão de múltiplos referenciais, observando-se a diversidade de perspectivas de compreensão do ser humano (CNE/CES, 2011). Assim, seria papel dos cursos de Psicologia propiciar ao aluno uma base geral sólida das diversas áreas da Psicologia, possibilitando a subsequente focalização do aluno na área que melhor the convier. Embora as organizações curriculares de cada curso sejam limitadas pelo tamanho e perfil do corpo docente, é preciso ter cuidado para que os vieses introduzidos no currículo pelas visões de Psicologia predominantes na instituição não limitem o desenvolvimento do aluno e assim não contribuam para o fenômeno da evasão.

\section{CONSIDERAÇÕES FINAIS}

Em síntese, este estudo permitiu identificar alguns fatores ou situações que podem levar à evasão do curso de Psicologia da UFRGS. Podemse destacar tanto fatores mais ligados a questões pessoais quanto fatores mais relacionados a questões institucionais. Mesmo que a universidade promova espaços de integração e apoio que possam amenizar problemas desta ordem, estas questões muitas vezes extrapolam a capacidade de ação da instituição, principalmente nas questões relacionadas à exploração vocacional, que são fundamentalmente prévias ao ingresso à instituição. Mais do que ações da universidade, estes problemas requerem intervenções que alcancem crianças e adolescentes ainda na escola e que divulguem questões como a importância do desenvolvimento de uma carreira, o desenvolvimento de habilidades necessárias ao mundo acadêmico e a importância de buscar informações sobre as profissões, além da própria exploração e reflexão sobre as características pessoais. Por outro lado, observam-se aspectos relacionados à evasão que são ligados diretamente à instituição e que, por consequência, podem ser trabalhados por ela, como aspectos relativos à qualificação de professores e questões curriculares.

Faz-se necessário destacar algumas limitações do estudo. A primeira é que não é possível fazer uma generalização dos resultados sobre os fatores de evasão. Os fatores elencados são referentes a seis indivíduos que ingressaram em um curso específico e em um período temporal específico (entre 2004 e 2009); mas como a lógica da pesquisa qualitativa trabalha a partir da plausibilidade e da verossimilhança, entende-se que os resultados aqui descritos ajudam a pensar questões em outros cursos e instituições que apresentem alguma similaridade de contexto. A segunda limitação é que o instrumento utilizado, adaptado da entrevista elaborada por Bardagi (2007), não foi criado para ser analisado a partir das categorias propostas. Talvez um instrumento criado especificamente com esse objetivo possa trazer outros elementos em algumas categorias que não apresentaram muita riqueza nas respostas. 
A ideia de se fazer a categorização a partir dos fatores elencados na literatura internacional teve como intuito verificar se, sob o prisma destas categorias, seria possível identificar fatores relacionados à evasão em uma amostra nacional. Mesmo com a limitação descrita acima, acredita-se que categorias baseadas neste modelo, somadas à observação necessária de aspectos vocacionais, possibilitaram uma compreensão abrangente da experiência universitária e da consequente evasão. Assim, indica-se que mais estudos sejam realizados com a busca deste diálogo com a literatura internacional, o que pode trazer novos elementos que sirvam para subsidiar a construção de um modelo de evasão aplicável ao contexto nacional.

\section{REFERÊNCIAS}

Andriola, W. B., Andriola, C. G. \& Moura, C. P. (2006). Opiniões de docentes e de coordenadores acerca do fenômeno da evasão discente dos cursos de graduação da Universidade Federal do Ceará (UFC). Avaliação e Políticas Públicas em Educação 14(52), 365382.

Bardagi, M. P. (2007). Evasão e comportamento vocacional de universitários: estudos sobre 0 desenvolvimento de carreira na graduação. Tese de Doutorado. UFRGS. Porto Alegre, RS.

Bardagi, M. P. \& Hutz, C. S. (2005). Evasão e serviços de apoio ao estudante: uma breve revisão da literatura brasileira. Psicologia Revista, 14, 279-301.

Bardagi, M. P., \& Hutz, C. S. (2008). Apoio parental percebido no contexto da escolha inicial e da evasão de curso universitário. Revista Brasileira de Orientação Profissional, 9(2), 31-44.

Bardagi, M. P., \& Hutz, C. S. (2012). Rotina Acadêmica e Relação com Colegas e Professores: Impacto na Evasão Universitária. Psico, 43(2), 174-184.

Bardin, L. (1979). Análise de conteúdo (L. A. Reto \& A. Pinheiro, Trans.). Edições 70/Livraria Martins Fontes. São Paulo, SP.

Berger J. B. \& Milem, J. F. (1999). The role of student involvement and perceptions of intergration in a causal model of student persistence. Research in Higher Education 40, pp. 641-664.

Cabrera, A., Nora, A., \& Castañeda, M. (1993). College persistence: structural equations modeling test of an integrated model of student retention. The Journal of Higher Education, 64(2), 123-39.

CNE/CES (2004). Resolução $n^{\circ} 08$, Diário Oficial da União, Brasília.
CNE/CES (2011). Resolução № 05 Diário Oficial da União, Brasília.

Comissão Especial de Estudos sobre Evasão. (1996). Diplomação, retenção e evasão nos cursos de graduação em IES públicas. Avaliação, 1(2), 55-65.

Gauer G., \& Gomes, W. B. (2002). O curso da reforma: ensino de psicologia na Universidade Federal do Rio Grande do Sul (1971-1979). Psicologia: Reflexão e Crítica, 15(3), 497-513.

Gomes, M. J., Monteiro, M., Damasceno, A. M., Almeida, T. J. S. \& Carvalho, R. B. (2010) Evasão Acadêmica no Ensino Superior: Estudo na Área da Saúde. Revista Brasileira de Pesquisa em Saúde, 12(1), 6-13.

Haussmann, L. R. M., Ye, F., Schofield, J. W. \& Woods, R. L. (2009). Sense of belonging and persistence in white and african american firstyear students. Research in Higher Education, 50(7), 649-669.

Mercuri, E. \& Polydoro, S. A. J. (2004). O compromisso com o curso no processo de permanência/evasão no Ensino Superior: algumas contribuições. Em E. Mercuri \& S. A. J. Polydoro (Orgs.). Estudante universitário: características e experiências de formação. (pp.219-236). Taubaté, SP: Cabral.

Palharini, F. A. (2008). Contornos da Evasão no Curso de Letras da UFF. Cadernos de Letras da UFF 36(1), 145-164.

Pascarella, ET, \& Terenzini PT (2005). How college affects students: $A$ third decade of research. San Francisco: Jossey-Bass.

Ribeiro, M. A. (2005). O projeto profissional familiar como determinante da evasão universitária: Um estudo preliminar. Revista Brasileira de Orientação Profissional, 6(2), 55-70.

Ristoff, D. I. (1999). Universidade em foco: reflexões sobre a educação superior. Florianópolis: Insular.

Robbins, S., Lauver, K., Le, H. , Davis, D., Langley, R. \& Carlstron, A. (2004). Do psychological and study skill factors predict college outcomes? A Meta - Analysis. Psychological Bulletin 130(2): 261-288.

Sameano F. P., Allen, J., Robbins, S. \& Phels, R. P. (2010). Predictors of Long-Term Enrollment and Degree Outcomes for Community College Students: Integrating Academic, Psychosocial, Socio-demographic, and Situational Factors. The Journal of Higher Education 81(6), 750-778.

Savickas, M.L. (1997). Career adaptability: An integrative construct for Life-Span, Life-Space Theory. The Career Development Quarterly, 45, 247-259.

Schleich, A.L.R.; Polydoro, S.A.J.; \& Santos, A.A.A. (2006). Escala de Satisfação com a Experiência Acadêmica de Estudantes do Ensino Superior. Avaliação Psicológica, 5(1), 11-20.

Silva Filho, R. L. L., Montejunas, P. R., Hipólito, O. \& Lobo M. B. C. M. (2007). A evasão no ensino 
superior brasileiro. Cadernos de Pesquisa, 37 (132), 642-659.

Silva, R. R. C. M., Mainier, F. B. \& Passos, F. B. (2006) A contribuição da disciplina de introdução à engenharia química no diagnóstico da evasão. Ensaio: Avaliação e Políticas Públicas em Educação, 14(51), 261-277.

Teixeira, M. A. P., Bardagi, M. P. \& Hutz, C. S. (2007). Escalas de exploração vocacional (EEV) para universitários. Psicologia em Estudo, 12, 195-202.

Teixeira, M. A. P., Dias, A. C. G., Wothich, S. H. \& Oliveira, A. M. (2008). Adaptação à universidade em jovens calouros. Psicologia Escolar e Educacional, 12(1), 185-202.

Teixeira M. A. P., Castro, A. K. S. S. \& Zoltowski, A. P. C. (2012) Integração Acadêmica e Integração Social nas Primeiras Semanas na Universidade: Percepções de Estudantes Universitários.
Gerais: Revista Interinstitucional de Psicologia, 5(1), 69-85.

Tinto, V. (1975). Dropout from higher education: A theoretical synthesis of recent research. Review of Educational Research 45: 89-125.

Alexandre Kurtz dos Santos Sisson de Castro: Psicólogo pela Universidade Federal do Rio Grande do Norte, mestre em Psicologia pela Universidade Federal do Rio Grande do Sul.

Marco Antônio Pereira Teixeira: Professor no Departamento de Psicologia do Desenvolvimento e da Personalidade no Instituto de Psicologia da Universidade Federal do Rio Grande do Sul. 